\title{
Formação profissional no Brasil: o papel do Serviço Nacional de Aprendizagem Industrial - SENAI
}

\author{
Professional Development in Brazil: \\ the role of the National Service of Industrial Training - SENAI
}

Luciano Pereira da SILVA ${ }^{\bullet}$

\begin{abstract}
Resumo: $O$ tema reestruturação produtiva tem sido foco de diversas pesquisas publicadas na área de Sociologia do Trabalho. O número de trabalhos que tratam de tal temática justifica-se pelas importantes transformações que o mundo do trabalho sofre nos últimos 20 anos em virtude da nova organização do sistema produtivo. No novo cenário que se apresenta, destaca-se uma importante agência de formação profissional: o Serviço Nacional de Aprendizagem Industrial - SENAI. Neste contexto, o estudo teve como objetivo geral discutir as mudanças no processo de qualificação profissional, tendo em vista as transformações do sistema produtivo capitalista. Além disso, foi investigada a contribuição do SENAI de Montes Claros para a qualificação de trabalhadores e o consequente ingresso no mercado de trabalho. Para isso, foram coletados dados com os egressos do curso Técnico em Eletromecânica da unidade do SENAI de Montes Claros.
\end{abstract}

Palavras-chave: SENAI; Formação profissional; Trabalho.

\begin{abstract}
The production restructuring theme has been the focus of several research papers published in the area of the sociology of labour. The numerous studies which have dealt with this subject are justified by the important transformations that the world of labour has undergone during the last 20 years in virtue of the new organization of the system of production. Within this new scenario an important agency of professional formation has appeared: the National Service of Industrial Training - SENAI. In this context, our study had as its general aim to discuss the changes in the process of professional qualification focusing on the transformations of the capitalist production system. In addition the contribution of the SENAI at Montes Claros was investigated with respect to worker qualification and their consequent entrance into the job market. Therefore information was collected from the students who had finished the electro-mechanics technical course at the Montes Claros SENAI unit.
\end{abstract}

Keywords: SENAI; Professional development; Labour.

\section{Introdução}

O Curso que fiz... achava que iria resolver o meu problema de emprego... porque até aquele dia, eu não tinha profissão. Um diploma, todo mundo diz, aumenta a nossa chance de subir na vida, não é?

O trecho acima é de autoria de um egresso do Serviço Nacional de Aprendizagem Industrial SENAI - especificamente no Curso Técnico em Eletromecânica. Um dos elementos da fala é intrigante: a crença generalizada de que a formação escolar é determinante no sucesso profissional.

\footnotetext{
- Doutorando em Educação - Programa de Pós-Graduação em Educação da UFMG. Professor - UNIMONTES Universidade Estadual de Montes Claros - Campus Universitário Professor Darcy Ribeiro, C.P. 126, Montes Claros, Minas Gerais, Brasil. E-mail: luciano.silva@unimontes.br
} 
Tal percepção, muito disseminada entre o senso comum, reflete a propaganda dos organismos internacionais e federais brasileiros.

É comum a defesa, através do discurso oficial do Estado, de que uma das principais causas do desemprego é a falta de formação profissional adequada. As políticas públicas educacionais vão ao encontro dessa afirmativa, amparadas, inclusive, por instituições internacionais de financiamento (Fundo Monetário Internacional - FMI e Banco Mundial - BIRD, por exemplo). Autores como Segnini (2000) vão afirmar, porém, que fenômenos como o crescimento do desemprego são, na verdade, oriundos das mudanças no mercado de trabalho, no sentido de que as transformações nos processos de produção de bens e serviços têm como consequência a menor oferta de postos de trabalho. Assim, entender as dificuldades e desafios do mundo do trabalho apresenta-se como um intrigante objeto de estudo.

Outra questão que motiva a realização desta pesquisa é o fato de que as transformações no modo de produção de bens, como a reestruturação produtiva, ainda carecem de mais estudos. Para Tumulo (2001), é preciso reconhecer que a conformação do fenômeno da reestruturação produtiva ainda é insatisfatoriamente conhecida no Brasil. O autor afirma também que analisar o processo de reestruturação produtiva neste país é uma tarefa difícil, sobretudo em virtude do fenômeno ser relativamente novo.

Com o intuito de abordar os novos requisitos exigidos do trabalhador pelo mercado de trabalho a partir do fenômeno conhecido como reestruturação produtiva, este trabalho ressalta a atuação de uma importante agência de formação profissional, o Serviço Nacional de Aprendizagem Industrial - SENAI, com ênfase na unidade de Montes Claros/MG. O SENAI começou a exercer atividades em Montes Claros/MG em fins dos anos 1980, oferecendo mão-de-obra para várias atividades e indústrias.

O objetivo geral deste trabalho é discutir as mudanças no processo de qualificação profissional, tendo em vista as transformações do sistema produtivo capitalista e investigar a contribuição do SENAI de Montes Claros para a qualificação de trabalhadores e o consequente ingresso no mercado de trabalho.

Para pesquisar os trabalhadores egressos do SENAI - Montes Claros - enfocamos os concluintes de cursos técnicos, por serem estes os cursos que visam oferecer não apenas uma profissionalização inicial, mas uma formação técnica para que o egresso possa ingressar no mercado de trabalho. Pelo fato dos cursos técnicos terem se iniciado na unidade de Montes Claros somente no ano de 2003, existiam, até o desenvolvimento dessa pesquisa, 51 alunos formados (Curso Técnico em Eletromecânica). Buscamos a realização de um censo, mas, devido à não-localização de alguns trabalhadores ou à recusa de outros em participar da pesquisa, foram coletados dados com 33 trabalhadores. 
O formulário aplicado aos egressos abarca questões objetivas e abertas. Algumas tratam da identificação da contribuição do SENAI para a prática profissional do trabalhador (tendo em vista o constante desenvolvimento técnico ligado à produção) e das capacitações profissionais realizadas pelos egressos. Outras buscam considerar a subjetividade dos sujeitos, ou seja, têm por objetivo interrogar acerca da obtenção do emprego ou em que medida o curso do SENAI foi ou não determinante para o ingresso no mundo do trabalho. Assim, os trabalhadores responderam baseados em suas impressões.

A pesquisa de campo e a discussão bibliográfica representam um esforço de compreensão do papel do SENAI para o ingresso dos indivíduos no mercado de trabalho, tendo em vista os frequentes e sucessivos redimensionamentos das exigências do mundo produtivo.

\title{
A formação profissional e o Sistema Nacional de Aprendizagem Industrial- SENAI
}

A educação profissional no Brasil inicia-se em 1909 com a criação de 19 escolas de artes e ofícios pelo Estado. Entretanto, a função dessas escolas não tinha relação com o processo de produção e com a industrialização que, aliás, praticamente inexistiam. Tais escolas de artes e ofícios possuíam, na verdade, o papel de retirar das ruas alguns excluídos, como pobres, órfãos e indigentes e dar-lhes uma formação moral (ARANHA, 1996).

A formação de trabalhadores foi, durante todo o século XX, uma opção para os pobres no

Brasil. À elite econômica havia a opção do curso primário, seguido pelo secundário com vistas ao ingresso no curso superior. Essa dualidade, ou seja, o direcionamento da elite para o ensino superior e o direcionamento da camada pobre da população para o ensino profissionalizante, marcava a separação daqueles que iriam desempenhar funções intelectuais ou instrumentais. Ao tratar dessa dualidade, Kuenzer afirma que

\begin{abstract}
A essas duas funções do sistema produtivo correspondiam trajetórias educacionais e escolas diferenciadas. Para os primeiros, a formação acadêmica, intelectualizada, descolada de ações instrumentais; para os trabalhadores, formação profissional em instituições especializadas ou no próprio trabalho, com ênfase no aprendizado, quase que exclusivo, de formas de fazer a par do desenvolvimento de habilidades psicofísicas (KUENZER, 2002, p.27).
\end{abstract}

Os anos 1930 marcaram um significativo crescimento urbano-industrial no Brasil. Entretanto, apesar das transformações que a economia brasileira passava, o sistema educacional permaneceu profundamente atrasado e ineficaz.

Após a Primeira Guerra Mundial, com a industrialização e a urbanização forma-se a nova burguesia urbana, e estratos emergentes de uma pequena burguesia exigem 
o acesso à educação. Retomando, porém, os valores da oligarquia, estes segmentos aspiram à educação acadêmica e elitista e desprezam a formação técnica, considerada inferior. $O$ operariado exige um mínimo de escolarização, e começam as pressões para a expansão da oferta de ensino (ARANHA, 1996, p.198).

Nesse contexto, surgiram os ideais conhecidos como escolanovistas que defendiam, entre outras coisas, a educação obrigatória e gratuita como dever do Estado e o combate ao sistema dual de ensino. Diversos grupos sociais vão entender, nesse momento, a educação como um instrumento de emancipação da sociedade e de busca de cidadania.

No sentido de oferecer educação profissional à parcela pobre da população brasileira, desenvolveram-se ações tanto da iniciativa privada quanto do setor público que visavam desenvolver esse tipo de formação.

A ampliação do ensino técnico no Brasil começa nos anos 1940, por meio de uma série de Leis Orgânicas:

a) 30/jan de 1942 - Decreto-lei $n^{\circ} .4 .073$ - Organizou o ensino industrial;

b) 28/dez de 1943 - Decreto-lei n ${ }^{\circ} .6 .141$ - Lei Orgânica do Ensino Comercial;

c) 20/ago de 1946 - Decreto-lei nº 9.613 - Lei Orgânica do Ensino Agrícola (ROMANELLI, 1982).

Nota-se que as duas primeiras legislações foram editadas em pleno Estado Novo e no contexto da $2^{\mathrm{a}}$ Guerra Mundial. Foi justamente nesse período que começou, no Brasil, a fase de substituição das importações, decorrentes muitas vezes das necessidades da guerra. Tal processo é justificado pelo fato de que era preciso satisfazer o desejo de consumo, num momento em que as importações de produtos industrializados estavam prejudicadas pelo já mencionado conflito bélico. A solução era expandir o setor industrial brasileiro e isso dependia, naturalmente, do crescimento da mão-de-obra.

A criação, em 1942, do SENAI e, em 1946, do Serviço Nacional de Aprendizagem Comercial - SENAC, buscava oferecer formação técnica ao trabalhador, necessidade condizente com o desenvolvimento industrial da metade do século XX. Nesse contexto, a criação do SENAI representa a decisão das indústrias em participarem do treinamento da mão-de-obra. Os cursos oferecidos pelo SENAI, sob a administração da Confederação Nacional das Indústrias, multiplicaram-se pelo país em meados do século $\mathrm{XX}$ e sobreviveram às reformas políticas educacionais posteriores.

A Reforma Capanema de 1942 reproduz a dualidade do sistema educacional brasileiro, estabelecendo, então, os cursos médios de $2^{\circ}$ ciclo para as elites, científico e clássico, com três anos de duração, preparando o estudante para o ingresso no ensino superior. Já a formação profissional 
começa a acontecer, também em nível médio de $2^{\circ}$ ciclo, através dos cursos agrotécnico e comercial técnico, entre outros, sempre possuindo terminalidade neles mesmos.

O projeto nacional de industrialização do governo do presidente Getúlio Vargas passou a englobar a preocupação com o preparo do trabalhador para o mercado. Esse preparo vai acontecer com a participação efetiva dos empresários, que vão gerenciar, junto com o governo, os recursos captados de maneira compulsória (frequentemente através de descontos em folha de pagamento). Segundo Pochmann (2000), além dos cursos de formação de curta e média duração apresentados por instituições setoriais (SENAI e SENAC, por exemplo), coube ao governo a difusão de cursos técnicos de longa duração (escolas federais, estaduais e universidades). O autor ressalta que, com isso, o país passa a contar com um modelo de formação profissional ancorado em bases, organizacional e financeira, que tendem a operar com características bem distintas.

A Lei de Diretrizes e Bases da Educação Nacional de 1961 trouxe mudanças significativas na educação nacional, com a integração entre o ensino profissional e o sistema regular de ensino. Porém, não podemos afirmar que a dualidade estava superada, pois os diferentes tipos de formação continuavam a possuir diferentes clientelas.

Apesar da Lei $n^{0}$ 5.692/1971 tentar implantar a profissionalização compulsória no Ensino Médio, no período da ditadura militar, tal iniciativa não obteve êxito devido às dificuldades de implantação do novo modelo e à crise econômica que o período conhecido como milagre econômico enfrentava.

Segundo Kuenzer (2002, p.30), dessa forma, "retoma à cena a velha dualidade estrutural, mesmo porque, originada na estrutura de classes, não pode ser resolvida no âmbito do projeto político pedagógico escolar".

A estrutura do sistema educacional brasileiro, apresentada anteriormente, obedece às exigências do modelo taylorista-fordista de produção ${ }^{1}$, atendendo a divisão social do trabalho (quando cada classe social deve ocupar uma determinada função pré-estabelecida) e a divisão técnica (parcelamento do processo produtivo em pequenas partes).

Para Kuenzer (2002), o princípio educativo que determinou o projeto pedagógico de formação profissional na organização taylorista-fordista baseia-se na concepção de formação profissional como processo individual, para a aprendizagem das formas de fazer definidas pelas necessidades da ocupação a ser exercida. A autora ressalta ainda que:

Nessa concepção, que fundamentou os cursos de treinamento das empresas, de qualificação profissional das agências formadoras e os médios profissionalizantes, o desenvolvimento das competências intelectuais superiores e o domínio do conhecimento científico tecnológico não se apresentavam como necessidade para os trabalhadores. Para estes, o conceito de competência profissional compreendia alguma escolaridade, treinamento para a ocupação e muita experiência, de cuja 
combinação resultava destreza e rapidez, como resultado de repetição e memorização de tarefas bem definidas, de reduzida complexidade e estáveis (KUENZER, 2002, p.31).

Com as mudanças no mundo do trabalho decorrentes do fenômeno da reestruturação produtiva $^{2}$, um novo projeto pedagógico foi adotado pelo governo. Uma das principais expressões desse novo projeto foi a Reforma do Ensino Técnico de 1996. As mudanças estabelecidas pela reformas são precedidas pelas Leis de Diretrizes e Bases - LDB (9394/96).

$\mathrm{Na}$ LDB/96, ao definirem-se as finalidades do Ensino Médio, buscam-se superar a dualidade socialmente estabelecida entre educação geral e educação profissional. O artigo, que trata do tema, afirma que as finalidades do Ensino Médio são

\footnotetext{
I - a consolidação e o aprofundamento dos conhecimentos adquiridos no Ensino Fundamental, possibilitando o prosseguimento de estudos;

II - a preparação básica para o trabalho e a cidadania do educando, para continuar aprendendo, de modo a ser capaz de se adaptar com flexibilidade a novas condições de ocupação ou aperfeiçoamento posteriores;

III - o aprimoramento do educando como pessoa humana, incluindo a formação ética e o desenvolvimento da autonomia intelectual e do pensamento crítico;

IV - a compreensão dos fundamentos científico-tecnológicos dos processos produtivos, relacionando a teoria com a prática, no ensino de cada disciplina.
}

Embora a legislação apresente uma unificação formal, não é possível negar que na prática continua existindo, assim como em toda a história da educação brasileira, duas redes de ensino destinadas a públicos diferentes.

A Reforma do Ensino Técnico é uma medida que faz parte de uma política mais ampla: a proposta do Sistema Nacional de Educação Tecnológica. Tal sistema justifica-se pela defesa de que, para atingir o desenvolvimento econômico, é necessário o uso de tecnologias modernas que, por sua vez, exigem recursos humanos capacitados. Assim, pautado no objeto principal, segundo o governo, de melhoria da oferta educacional e de sua adequação à nova realidade econômica, buscase uma articulação entre os Centros Federais de Educação Tecnológica - CEFETs, SENAI, SENAC, universidades e demais instituições envolvidas no ensino técnico.

Kuenzer (2002) afirma que a Reforma do Ensino Técnico segue a lógica das políticas educacionais, sendo regida pela racionalidade financeira. Além disso, tais políticas repousam não mais no reconhecimento da universalidade do direito à educação em todos os níveis, mas no princípio da equidade, que significa tratamento diferenciado de acordo com as demandas da economia. O investimento em educação é norteado pela ideia de que o Estado só pode arcar com as despesas que resultem em retorno econômico.

Acerca da Reforma do Ensino Técnico (Lei 1.603/96), Ferreti (1996) diz que esta insiste que, num primeiro plano, pela via do sistema público de ensino menos flexível, ocorra a formação de 
caráter geral, terreno básico sobre o qual se construirão as capacitações profissionais. Num segundo plano, tal construção deve ser realizada de modo ágil e flexível, pelas agências de formação profissional, para atender urgentemente às demandas dos diferentes setores econômicos, sobretudo os que vêm introduzindo novas tecnologias.

A expansão e a elevação da escolaridade devem ser metas, não como meio de atribuição de empregabilidade, mas principalmente porque a ampliação quantitativa e qualitativa da educação apresenta-se como exigência da ampliação dos direitos de cidadania, como pressuposto à implementação e consolidação do processo democrático no país (MORAES, 1999, p.26).

Além das críticas já apresentadas anteriormente, podemos mencionar também o processo de implantação da referida reforma. Apesar de o Ministério do Trabalho estar realizando amplo debate sobre as reformas que deveriam ser implantadas na educação profissional brasileira, tais discussões foram ignoradas na apresentação de anteprojeto de Lei pelo Ministério da Educação e Cultura MEC. Dessa forma, o texto apresentado no anteprojeto foi construído basicamente por técnicos do Ministério, sem a participação dos diversos atores envolvidos na reforma. Destaca-se também a crítica acerca da influência de organismos financeiros internacionais em todo o processo, sobretudo do Banco Mundial.

Moraes (1999) afirma que outro problema acerca da reforma é a atribuição ao MEC, com recursos públicos, do financiamento da capacitação profissional voltada para ocupações definidas do mercado de trabalho, através dos cursos modulares que dão direito a um Certificado de Qualificação Profissional. Além de destacar que esta, sem dúvida alguma, não é uma função do MEC, a autora também ressalta que

Historicamente, o setor produtivo pouco recorreu ao Estado para a qualificação de seus trabalhadores em face da especificidade dos processos produtivos, do segredo industrial, da competitividade, da rapidez, da dinamicidade do mercado. Para isto constituiu sua própria rede, financiando-a com recursos públicos, mas que são apresentados como provenientes do setor privado (MORAES, 1999, p.76).

$\mathrm{Na}$ nova conformação do processo de formação profissional, percebemos que, com a reestruturação produtiva, o trabalhador não mais adquire uma habilidade profissional como no modelo fordista/taylorista de produção, quando ela era adquirida durante a sua formação e exercida ao longo da vida. Agora, o trabalhador está em constante processo de formação e preparo para o trabalho. Nunca é demais questionar se tal fato é realmente uma nova característica da produção oriunda das transformações econômicas ou se é muito mais uma justificativa para a exclusão de um modelo produtivo em que não há postos de trabalho para todos. 
Os impactos da modernização tecnológica no campo do trabalho bem como a reestruturação produtiva das últimas décadas são assuntos que ainda não estão esgotados e que suscitam diversas polêmicas. Além disso, não podemos esquecer que os impactos dessas mudanças são sentidos em intensidades diferentes de um país para outro e dentro de um mesmo país. Há países, por exemplo, os quais, assim como o Brasil, possuem tanto empresas que trabalham com a mais avançada tecnologia de ponta como empresas que lidam com tecnologias completamente obsoletas.

\section{A implantação do SENAI no Brasil}

As reformas educacionais que acontecem a partir de 1930 voltam-se no sentido de uma orientação política educacional sintonizada com o mundo capitalista. A crescente industrialização provocou a necessidade, cada vez maior, de trabalhadores com formação técnica para ocuparem postos industriais. Nesse sentido, o Decreto-Lei 4048, de 22 de janeiro de 1942, cria o SENAI. Tal decreto é parte integrante das Leis Orgânicas de Ensino que vão promover reformas na educação entre 1942 e 1946, conhecidas também como Reforma Capanema, em virtude de terem sido implementadas pelo ministro Gustavo Capanema.

As Leis Orgânicas de Ensino reforçam características da educação brasileira afirmadas pela Constituição de 1937, algumas delas presentes em toda a história da república. Na Constituição, há a clara distinção entre o trabalho intelectual voltado às classes mais favorecidas e o trabalho manual (estimulado também pelo ensino profissional) voltado às classes menos favorecidas.

A criação do SENAI, além de buscar suprir a necessidade da formação de mão-de-obra, passa parte da responsabilidade da formação do trabalhador para os empresários. Tal fato demonstra também a aproximação da burguesia industrial com o Estado, e a crença no crescimento da indústria como caminho para o desenvolvimento da economia.

Desde sua fundação, o SENAI possui seus objetivos e organiza sua lógica de funcionamento de acordo com as dinâmicas das atividades financeiras nacionais. Tal fato fica evidente no artigo 27 do Regimento Interno do SENAI, aprovado em 16 de julho de 1942. De acordo com o referido artigo, as escolas e cursos de aprendizagem industrial seriam instituídos e entrariam em funcionamento gradual, de acordo com as necessidades e conveniências da economia nacional.

A participação de instituições não-governamentais na formação do trabalhador constitui-se, atualmente, em uma das tarefas do Sistema "S". Para Evangelista (2000), esse sistema, composto por instituições educacionais e assistenciais, administradas pelas entidades patronais dos setores da indústria, comércio, transporte e agricultura, é financiado através da contribuição compulsória retirada da folha salarial das empresas vinculadas a essas entidades. Além disso, as entidades que 
integram o Sistema "S" têm contado também com o financiamento proveniente dos recursos do Fundo de Amparo ao Trabalhador (FAT) ${ }^{3}$.

A preparação oferecida pelo SENAI atende ao setor secundário da economia, sendo os cursos mantidos por contribuição compulsória dos trabalhadores das indústrias. Recursos públicos são captados, destinando para a aprendizagem industrial $1 \%$ do total da folha de pagamentos e mais 0,2\% de empresas com mais de 500 funcionários. Financiado com recursos públicos, mas administrado pela iniciativa privada, assim se organiza a maior rede de preparação do trabalhador para a indústria no Brasil. Tais cursos voltam-se essencialmente para atividades práticas e desenvolvem-se fora do sistema regular de ensino.

Em sua estrutura administrativa interna, o SENAI possui o Conselho Nacional e os Conselhos Regionais, ambos responsáveis pela definição das políticas da instituição. Já o Departamento Nacional e os Departamentos Regionais são responsáveis pela execução de tais políticas.

Com seu desenvolvimento, o ensino profissionalizante ocupa um lugar específico dentro do dualismo do sistema educacional brasileiro, adequado agora à nova dinâmica da sociedade que se molda às transformações econômicas.

A nova força de trabalho precisa ser recrutada dentro da nova configuração da sociedade e classes. Evidentemente não será fornecida pela classe dominante, na qual continuam configurando, mesmo com seu poder reduzido, a velha aristocracia rural, a burguesia financeira e a nova burguesia industrial em ascensão. Assim as escolas técnicas vão ser a escola para os filhos dos outros, ou melhor, a única via de ascensão permitida aos operários. Que essa via é falsa e se revela um beco sem saída está implícito na especificidade desta escola. Sendo de nível médio ela não habilita seus egressos a cursarem escolas de nível superior. Criou-se a dualidade do sistema educacional que além de produzir e reproduzir a força de trabalho para o processo produtivo, garante a consolidação e a reprodução de uma sociedade de classes (FREITAG, 1986, p.22).

Na última década do século XX, o debate sobre o SENAI centra-se no papel que ele assume frente ao desenvolvimento das modernas tecnologias de produção e, sobretudo, diante da Reforma do Ensino Técnico. Principalmente a partir de 1996, o SENAI passa por uma série de mudanças, adequando suas ações às transformações sofridas pelo mercado de trabalho. Tais mudanças atendem, inclusive, às sugestões apresentadas pelos organismos internacionais (Banco Internacional de Reconstrução e Desenvolvimento - BIRD; Banco Interamericano de Desenvolvimento - BID) para que o SENAI contribua melhor para os interesses capitalistas. Quando o Governo Federal, através de políticas educacionais decorrentes da reforma, assume a aprendizagem industrial, como já foi abordado anteriormente, o SENAI tenta eliminar sua ambiguidade público/privado e busca a auto-sustentação. Assim, ele pode dedicar-se a oferecer os cursos que o mercado parece demandar com maior intensidade e para os quais está disposto a pagar (CUNHA, 1997). 
Pelas orientações do MEC, as escolas técnicas também devem seguir a lógica do SENAI, separando o ensino acadêmico do ensino técnico-profissional e sofrendo grande influência administrativa do setor produtivo. É defendido que os empresários podem orientar melhor os caminhos que o ensino técnico deve seguir.

A adoção de pressupostos dos organismos multilaterias na ordenação das políticas educacionais do país é, pois, bastante clara. As preocupações com a identidade do ensino médio e a otimização da relação custo-benefício direcionam o processo de reorientação desse nível do ensino básico que culminou na proposta de sua flexibilização. Referenciando-se no Senai, o MEC promoveu a "desescolarização" do ensino técnico e determinou, nas instituições públicas de ensino profissional, a oferta de cursos modulares de qualificação, de curta duração e completamente dissociados da educação básica, destinados à população adulta de baixa escolaridade (MORAES, 1999, p.73).

A autora citada acima afirma também que nessa perspectiva abre-se a possibilidade de as escolas técnicas transformarem suas atividades educativas em serviços a serem vendidos, especialmente às empresas. A reforma então, além de promover o desmonte do sistema público de ensino técnico, estimula sua privatização.

Nessa nova realidade, a formação profissional se dá através de uma aproximação entre a rede de ensino técnico e as empresas. Para atender aos interesses empresariais, as escolas técnicas devem oferecer cursos fechados, voltados para atender a demandas específicas, direcionando suas atividades para o atendimento de interesses privados. Para Moraes (1999, p.79), o Decreto $\mathrm{n}^{\circ}$ 2.208/97 desqualifica o ensino da rede pública, interfere negativamente nas condições de funcionamento e na própria atribuição das escolas técnicas federais e reduz a formação tecnológica a treinamento fragmentado, demarcado pelas necessidades mais estreitas do capital.

O SENAI possui 627 Unidades Operacionais próprias, sendo que 227 (36,2\%) estão localizadas na região sudeste. Já a região nordeste caracteriza-se pela grande quantidade de unidades móveis $(33,76 \%)$, veículo de atuação significativa no interior do país. Com relação aos cursos oferecidos, a maior proporção de atendimentos se realiza no setor metal-mecânico, seguido do eletroeletrônico (MORAES, 1999).

Atualmente, o SENAI possui dois tipos de cursos profissionalizantes: os de formação inicial e os de formação técnica.

A formação inicial pode acontecer em 4 modalidades, segundo diferentes objetivos: 
QUADRO 01

Modalidades de cursos de formação inicial oferecidos pelo SENAI

\begin{tabular}{c|c}
\hline Modalidades & Objetivos \\
\hline Qualificação Profissional & $\begin{array}{r}\text { Preparar o aluno para uma profissão, incluindo trabalhadores que } \\
\text { procuram uma nova qualificação devido às mudanças tecnológicas } \\
\text { e organizacionais do processo produtivo. }\end{array}$ \\
Aperfeiçoamento & Atualizar os conhecimentos profissionais que o trabalhador já \\
pspecialização & Proporcionar um aprofundamento nos conhecimentos profissionais \\
que o trabalhador possui. & Proporcionar a aprendizagem inicial na área industrial. \\
\hline
\end{tabular}

Já a formação técnica de nível médio pode acontecer em 3 modalidades:

QUADRO 02

Modalidades de formação técnica oferecidas pelo SENAI

\begin{tabular}{c|c}
\hline Modalidades & Definição \\
\hline Qualificação Profissional & É obtida a partir da conclusão de módulos \\
& que compõem o Curso Técnico; o aluno conclui \\
& apenas parte da formação técnica (saídas \\
& intermediárias). \\
Especialização & É o aprofundamento dos conhecimentos \\
médio) & profissionais obtidos no curso técnico. \\
& É o curso que visa à formação técnica em \\
& determinada área profissional; para ingressar nesta \\
& modalidade, é necessário estar cursando ou ter \\
& concluído o ensino médio, sendo que o diploma de \\
& técnico só é fornecido a quem comprovar a \\
& conclusão do ensino médio.
\end{tabular}

\section{O SENAI em Montes Claros/MG}

$\mathrm{Na}$ cidade de Montes Claros, o SENAI vai exercer suas atividades somente a partir do final dos anos 80. A existência de uma unidade do SENAI em Montes Claros começa a tornar-se 
realidade em 1987, quando o empresário Luiz de Paula doa um terreno para o departamento Regional do SENAI. Em maio de 1998, é inaugurada a unidade que recebe o nome de Luiz de Paula. Tal Centro de Formação Profissional funciona em uma área de $3.804 \mathrm{~m}^{2}$, e possui salas de aula, oficinas, administração, laboratórios e área esportiva. A partir do ano de 2001, o SENAI Montes Claros desvincula-se da Escola Técnica e centraliza a oferta de cursos de qualifícação.

Em 2001 e 2002, o SENAI - Montes Claros, ofereceu apenas cursos de formação inicial. A partir do ano de 2003, inicia-se a oferta de cursos técnicos (nível médio). Atualmente, a unidade de Montes Claros forma técnicos em Eletrônica e em Eletromecânica.

O curso de Técnico em Eletrônica envolve a área do conhecimento que emprega eletrônica analógica, eletrônica digital, eletrônica de potência e microprocessadores. O técnico em Eletrônica desenvolve soluções com informações atualizadas referentes às modernas tecnologias, orientandose por desenhos, esquemas, normas e especificações técnicas. Utiliza instrumentos e métodos adequados para cooperar no desenvolvimento, instalação, montagem, funcionamento e reparo de equipamentos (SENAI, 2004).

Já o curso Técnico em Eletromecânica forma profissionais polivalentes e preparados para a necessidade do mercado, com capacidade de planejar, coordenar e executar a manutenção de sistemas eletromecânicos industriais. $\mathrm{O}$ aluno interage no processo produtivo, melhorando a qualidade do produto e garantindo suas especificações, trabalhando para cumprir as normas de segurança, ambientais e de higiene (SENAI, 2004).

\section{Considerações sobre os egressos do curso técnico em eletromecânica do SENAI - Montes}

\section{Claros}

Nessa seção são apresentados os dados coletados na pesquisa de campo com egressos do SENAI. Os dados referem-se a características pessoais (como sexo e situação profissional) e a dados da trajetória profisssional (motivo de contratação, relações de cursos de capacitação frequentados, entre outros). A análise dos dados busca discutir a contribuição do curso técnico frequentado para a prática profissional.

Os gráficos, tabelas e quadros apresentados referem-se aos dados coletados com 33 egressos do curso Técnico em Eletromecânica. Os cursos técnicos concluídos pelos egressos referem-se ao período entre 2003 e 2005. Os demais cursos foram realizados em períodos diversos e, inclusive, em outras unidades do SENAI. Já os treinamentos/cursos oferecidos pelas empresas não foram, necessariamente, em parceria com o SENAI. 
GRÁFICO 01: Sexo dos egressos

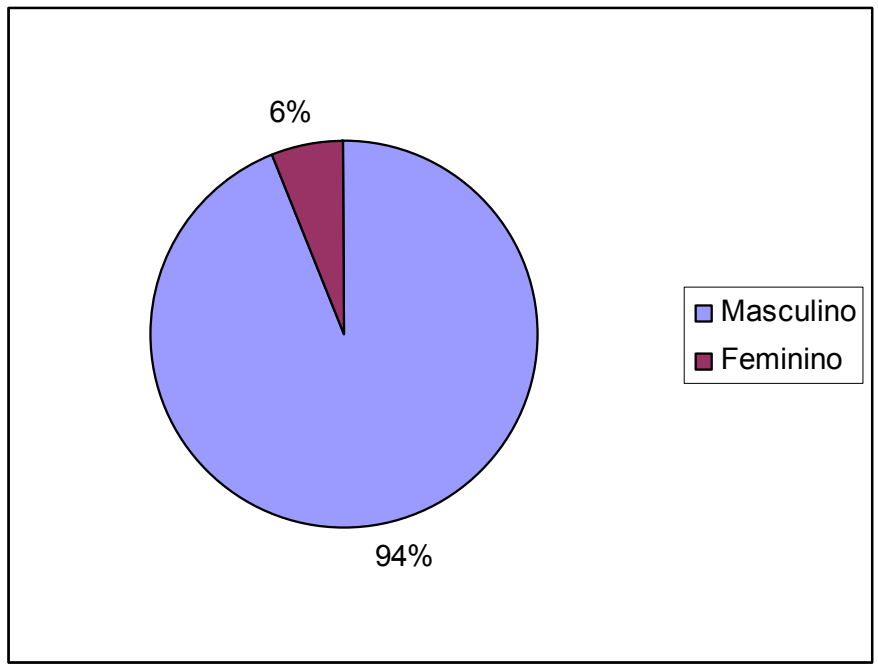

O GRAF. 01 reproduz uma característica marcante do SENAI que é o atendimento, sobretudo ao universo masculino. Tal fato retrata a situação das indústrias brasileiras, pois, segundo pesquisa do Departamento Intersindical de Estatística e Estudos Socioeconômicos - DIEESE (2006), no início deste século, dentre as mulheres que trabalhavam, apenas cerca de 9\% exerciam suas atividades profissionais em indústrias. É preciso lembrar, também, que o curso analisado (Técnico em Eletromecânica) é frequentemente considerado como uma habilidade masculina, o que também justifica a reduzida presença feminina.

Em pesquisa, que procurou diagnosticar a formação profissional brasileira no ramo industrial metalúrgico, Moraes (1999) constatou que o setor metal-mecânico é um universo marcadamente masculino. Para a autora, a restrita presença de mulheres nos cursos do SENAI dessa área pode estar relacionada ao fato de que, historicamente, nesse setor, as tarefas demandadas aos trabalhadores exigiam deles força física acentuada, tornando o trabalho mais rude e não apropriado para mulheres. Entretanto, é preciso assinalar que as mudanças técnicas no âmbito do trabalho tornaram as atividades exercidas no setor metal-mecânico menos dependentes da força física.

Se analisarmos as competências a serem desenvolvidas estipuladas no currículo do curso Técnico em Eletromecânica, podemos observar que, a princípio, elas não estão relacionadas a habilidades direcionadas ao universo masculino. Assim, não se justifica a composição do corpo discente do curso predominantemente por trabalhadores do sexo masculino. 
GRÁFICO 02: Situação profisssional dos egressos

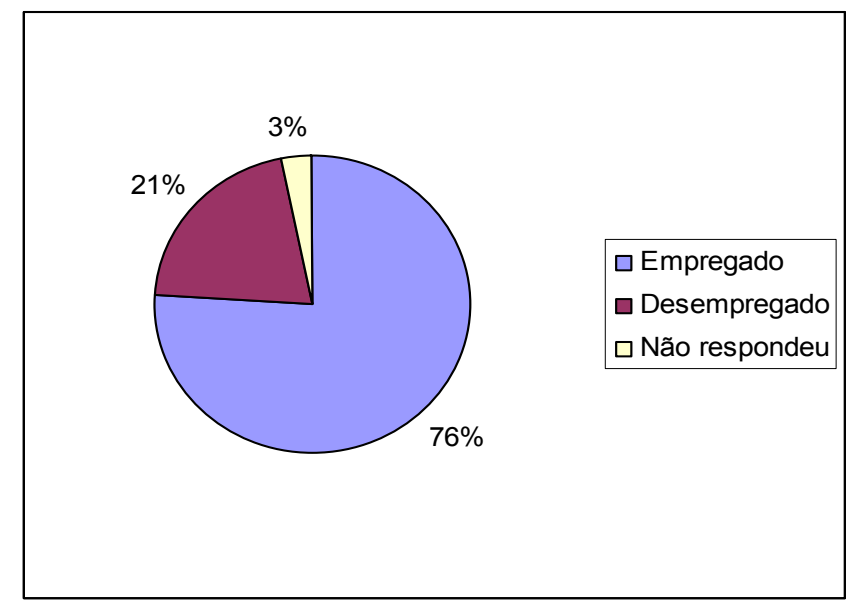

Apesar de 2/3 dos egressos do curso técnico analisado estarem empregados, o curso realizado só foi determinante para a admissão de metade desses (GRAF. 03). Uma discussão importante sobre esse aspecto diz respeito, segundo Moraes (1999), ao fato de o SENAI ter a opção política de não atender o desempregado. Com isso, a instituição contribui para o desenvolvimento das indústrias brasileiras, mas contribui de maneira insignificante para a diminuição da desigualdade social e para o ingresso no sistema produtivo de indivíduos excluídos desse processo. Outro aspecto que exclui uma parte significativa da população brasileira dos cursos técnicos é a exigência da sua realização após ou concomitante o segundo grau. Com isso, muitos indivíduos ficam impossibilitados de conciliar a formação profissional com o trabalho, impedindo a frequência em tais cursos. De acordo com Deluiz (2001), além de uma forma de elitização do ensino técnico-profissional, a exigência de conclusão ou de realização concomitante do ensino médio para a frequência no ensino técnico revela um mecanismo de contenção ao ingresso no nível superior.

Uma das transformações mais significativas que o SENAI vem passando é a elevação da exigência do grau de escolaridade para ingresso em seus cursos. Tal fenômeno acontece inclusive com a progressiva extinção da modalidade aprendizagem, com a concentração de esforços na formação de técnicos e com a instalação de cursos de curta duração. Com isso, a instituição está excluindo de sua clientela parcelas substantivas da população, dada a baixa escolaridade média da população brasileira (MORAES, 1999).

Já Kuenzer (2002) afirma que este é um dos efeitos positivos, mesmo que por contradição, da reestruturação produtiva. Segundo a autora, nessa nova realidade, constata-se a necessidade de pelo menos 11 anos de educação escolar para uma participação social, política e produtiva. 


\section{TABELA 01}

Ocupações profissionais que os egressos possuem ou possuíram após a realização do curso Técnico no SENAI

\begin{tabular}{lc}
\hline Ocupações & Ocorrência \\
\hline Não possuiu & 5 \\
Atua na área elétrica & 4 \\
Manutenção mecânica & 4 \\
Mecânico de automóveis & 4 \\
Auxiliar de manutenção mecânica & 3 \\
Técnico em eletromecânica & 3 \\
Auxiliar de produção & 2 \\
Ajustagem mecânica & 1 \\
Assessoria em serviços [condução de veículos] & 1 \\
Construção de rede de transmissão rural e urbana & 1 \\
Encarregado de auto de linha & 1 \\
Encarregado de manutenção de materiais & 1 \\
hidráulicos & 1 \\
Indústria metal mecânica & 1 \\
Manutenção elétrica, alvenaria, soldagem & 1 \\
Manutenção na área elétrica, hidráulica e mecânica & 1 \\
No comércio (padaria) & 1 \\
Oficial de eletromecânica [COPASA] & 1 \\
Operação de máquina & 1 \\
Projetista de estrutura metálica & 1 \\
Soldador & 1 \\
Vendedor de materiais elétricos & 1 \\
Total & 1 \\
\hline & 1 \\
\hline
\end{tabular}

A TAB. 01 apresentada acima retrata a grande variabilidade de ocupações que os egressos do curso técnico possuíram. Tal fato pode estar relacionado às novas características profissionais advindas da reestruturação produtiva quando o trabalhador, possuindo uma formação flexível, pode desempenhar diferentes funções. Para Pochmann (2000), o novo modelo de produção baseado na acumulação flexível proporciona uma nova organização das tarefas, em que há uma ampliação da 
quantidade de tarefas exercidas pelo trabalhador e uma rotação de funções, que exigem sua maior polivalência.

Entretanto, uma outra interpretação pode ser feita: a de que o curso técnico não garante um emprego na área de formação e que, com isso, o trabalhador acaba tendo que se sujeitar ao desempenho de diferentes funções para garantir a sobrevivência.

Outra questão direciona-se ao fato de que a rotação de funções e a polivalência do trabalhador não são, necessariamente, características que começaram a fazer parte da realidade brasileira a partir da reestruturação produtiva. Tendo em vista que o Brasil nunca possuiu em seu processo produtivo uma rigidez das relações de trabalho, podemos afirmar que o mercado de trabalho brasileiro, se medido pela rotatividade da mão-de-obra, sempre foi flexibilizado (SEGNINI, 2000).

TABELA 02

Capacitações profissionais realizadas pelos egressos no SENAI

\begin{tabular}{lc}
\hline Capacitações & Ocorrências \\
\hline Técnico em eletromecânica & 29 \\
Eletricista de baixa tensão & 2 \\
Mecânica de manutenção & 2 \\
Ajustagem mecânica & 1 \\
Capacitação energética & 1 \\
Curso de automação & 1 \\
Curso de manutenção industrial & 1 \\
Curso de eletroeletrônica & 1 \\
Excelência no atendimento & 1 \\
Informática & 2 \\
Mecânica de automóveis & 1 \\
Mecânica de usinagem & 1 \\
Mecânica geral & 1 \\
Mecânico de refrigeração industrial & 1 \\
Programador de CNC & 1 \\
Técnico em eletrônica & 1 \\
Tecnologia de produtos e equipamentos de segurança & 1 \\
Tornearia mecânica & 1 \\
Total & $\mathbf{4 9}$ \\
\hline
\end{tabular}


A existência de diversas capacitações profissionais realizadas pelos egressos do SENAI, além do curso técnico, reflete uma característica imposta à formação profissional pelo novo modelo de produção que, segundo Deluiz (2001), instiga os trabalhadores à formação contínua. Nessa nova realidade, a empregabilidade é centrada no trabalhador, sendo a responsabilidade de garantir o emprego uma tarefa individualizada. Além disso, a interdisciplinaridade, também presente nessa nova lógica, amplia as possibilidades de cursos feitos.

\section{GRÁFICO 03:}

Afirmação ou negação quando questionados se o curso Técnico foi determinante para a admissão em ocupação profissional

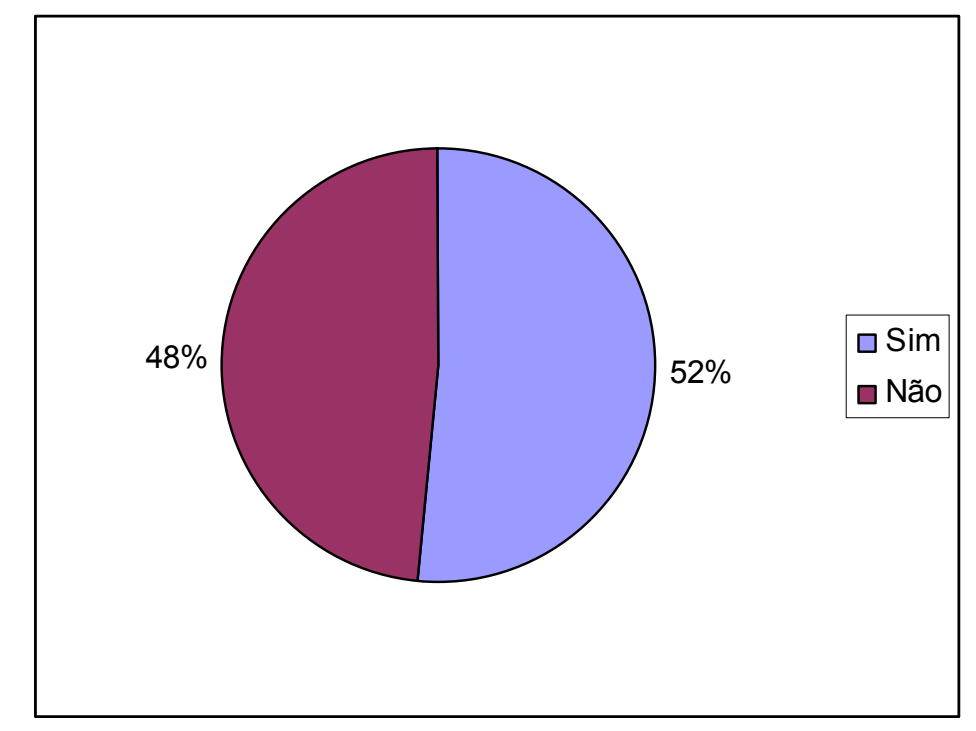

Como podemos observar no GRAF. 03, quase metade dos egressos do curso técnico analisado afirmam que tal curso não foi determinante para a admissão em ocupação profissional. De acordo com Moraes (1999), a estrutura administrativa do SENAI permite que a instituição opere em estreita colaboração com as indústrias de suas respectivas áreas, buscando atender às demandas do mercado de acordo com as particularidades de cada região. Tendo em vista que esses cursos são oferecidos a partir da necessidade apresentada pelas indústrias através de pesquisa prévia, podemos afirmar que é significativa a parcela dos egressos que não obteve ocupação profissional em virtude do curso. 
TABELA 03

Contribuição do Curso Técnico feito para a prática Profissional na opinião dos egressos

\begin{tabular}{lc}
\hline Contribuição & Ocorrências \\
\hline Trabalhos com eletricidade & 3 \\
Em tudo & 2 \\
Teoria & 4 \\
Não contribui & 2 \\
Aperfeiçoou a prática e o conhecimento que já possuía & 4 \\
Identificação dos materiais (peças, máquinas, ferramentas) & 7 \\
Trabalhos com soldagem & 3 \\
Não trabalha na área & 3 \\
Conhecimento geral & 3 \\
Trabalhos com mecânica & 4 \\
Prática & 3 \\
\hline
\end{tabular}

Percebe-se, com os dados apresentados na TAB. 03, a dificuldade dos egressos na identificação de aspectos técnicos da produção que receberam contribuição a partir do curso técnico frequentado. Tal fato pode relacionar-se à formatação do curso basear-se no modelo de competência em que, segundo Ferretti (1996), é enfatizado menos a posse dos saberes técnicos e mais a sua mobilização para a resolução de problemas e o enfrentamento de imprevistos na situação de trabalho. De acordo com Deluiz (2001), no novo contexto da reestruturação produtiva, a qualificação real dos trabalhadores é muito mais difícil de ser observada e constitui-se mais no saber-ser do que no saber-fazer. Para a autora, o conjunto de competências colocado em ação em uma situação prática de trabalho, a articulação dos vários saberes provenientes de várias esferas (formais, informais, teóricos, práticos, tácitos) para solucionar problemas e enfrentar situações de imprevisibilidade, a mobilização da inteligência para enfrentar os desafios do trabalho, são características desta qualificação real.

Além disso, a contribuição do curso técnico para a prática profissional pode ser percebida de maneiras e intensidades diferentes entre os diversos trabalhadores. Para Leite e Rizek (1997, p.178), tal fato relaciona-se "às diferentes formas de inserção de trabalhadores e trabalhadoras no processo produtivo, as quais se relacionam por sua vez a distintos padrões de uso do trabalho e a trajetórias diferenciadas de reestruturação".

Nas tabelas a seguir, são apresentados alguns cruzamentos realizados com os dados coletados. 


\section{TABELA 04}

Ano de admissão no último/atual emprego segundo capacitações profissionais realizadas no SENAI

\begin{tabular}{c|ccc}
\hline Ano de & \multicolumn{3}{|c}{ Ano da capacitação } \\
\cline { 2 - 4 } Admissão & 2003 & 2004 & 2005 \\
\hline 1984 & - & - & - \\
1986 & - & - & - \\
1994 & - & - & 2 \\
1995 & - & - & 2 \\
1997 & - & 1 & - \\
1998 & - & - & - \\
2000 & - & - & 1 \\
2001 & - & - & 2 \\
2002 & - & 1 & 1 \\
2003 & - & - & - \\
2004 & 1 & 3 & 2 \\
2005 & - & - & 3 \\
2006 & - & - & 4 \\
Total & $\mathbf{1}$ & $\mathbf{5}$ & $\mathbf{1 7}$ \\
\hline
\end{tabular}

A TAB. 04 acima ilustra a aproximação entre o SENAI e as indústrias, pois muitos trabalhadores realizaram o curso técnico já como funcionários da empresa onde trabalham. Outro aspecto reafirmado por esse dado, é a opção do SENAI de não atender o trabalhador desempregado (MORAES, 1999). 
TABELA 05

Quantidade de cursos realizados na empresa segundo situação

Profissional

\begin{tabular}{c|c|c|c|c}
\hline \multirow{2}{*}{ Quantidade } & \multicolumn{3}{|c|}{ Situação profissional } & Total \\
\cline { 2 - 5 } & Empregado & Desempregado & $\begin{array}{c}\text { Não } \\
\text { respondeu }\end{array}$ & \\
\hline 0 & 13 & 6 & - & 19 \\
1 & 2 & - & - & 2 \\
2 & 6 & - & 1 & 7 \\
3 & 3 & - & - & 3 \\
4 & 1 & 1 & - & 2 \\
Total & $\mathbf{2 5}$ & $\mathbf{7}$ & $\mathbf{1}$ & $\mathbf{3 3}$ \\
\hline
\end{tabular}

A TAB. 05 aponta que os trabalhadores que frequentaram cursos oferecidos pela própria empresa tiveram mais chances de manterem seus empregos. A constante atualização profissional, denominada por muitos de formação contínua, está fortemente presente no mundo do trabalho a partir da reestruturação produtiva. Entretanto, nem todas as empresas apostam em uma pedagogia interna, com o oferecimento de cursos pela própria empresa, para capacitarem sua força de trabalho. Há aquelas que, via de regra, preferem recorrer às agências de formação profissional. Para Deluiz (2001, p.2), "o capital humano das indústrias precisa ser constantemente mobilizado e atualizado para garantir o diferencial ou a vantagem competitiva necessários à desenfreada concorrência na economia internacionalizada".

\section{TABELA 06}

Determinação do curso do SENAI para a admissão profissional, segundo situação profissional

\begin{tabular}{lcccc}
\hline \multicolumn{5}{c}{ Situação atual } \\
\hline O curso foi & & & & \\
determinante & Empregado & Desempregado & Sem resposta & Total \\
Sim & 15 & 1 & 1 & 17 \\
Não & 10 & 6 & 0 & 16 \\
Total & $\mathbf{2 5}$ & $\mathbf{7}$ & $\mathbf{1}$ & $\mathbf{3 3}$ \\
\hline
\end{tabular}

Os dados apresentados acima mostram que o curso técnico apresenta-se como um importante fator de permanência no emprego, pois apenas um trabalhador encontra-se desempregado dentre aqueles que consideraram o curso determinante para a admissão. A aproximação das indústrias com 
as instituições de formação profissional, em especial o SENAI, contribui para essa realidade, pois as empresas podem imprimir nos cursos de formação a exata configuração que interessa ao processo produtivo.

A discussão dos dados apresentados buscou investigar, através da opinião dos egressos, as diversas significações que o curso técnico analisado possuiu na trajetória profissional destes. Além disso, pretendeu-se também debater as características que o curso técnico possui, tendo em vista as novas exigências impostas à formação profissional pela reestruturação produtiva.

\section{Considerações Finais}

A reestruturação produtiva provoca diversas alterações na dinâmica da formação profissional no Brasil. Em nome da busca pelo desenvolvimento econômico, os cursos de preparação para o trabalho oferecidos, tanto pelo Estado como pela iniciativa privada, vão adaptar-se às novas diretrizes impostas pelo capital internacional.

O SENAI, como uma das principais instituições de formação profissional do Brasil, frequentemente está no centro dos debates relacionados às mudanças que o processo de trabalho capitalista tem sofrido nos últimos 20 anos. Tais discussões direcionam-se, sobretudo, para o papel que essa instituição assume diante de um novo modelo de organização do processo de trabalho.

Percebendo, através do estudo do SENAI, uma estreita relação entre escola e empresa, podemos questionar se o sistema educacional brasileiro não está ratificando a polêmica e, ao mesmo tempo, a dicotomia, entre os cursos profissionalizantes e o Ensino Médio. Inicialmente pelo fato de que, na prática, é mantida a existência de duas trajetórias educacionais: o ensino superior para a elite e o ensino profissionalizante para as camadas pobres da população. Além disso, o próprio ensino profissionalizante possui duas possibilidades. De um lado existe a formação oferecida pelo SENAI, em proximidade com as empresas e, consequentemente, em maior conformidade às exigências das novas tecnologias capitalistas; de outro lado, a formação oferecida pelo Estado, frequentemente com recursos do FAT, com caráter compensatório ou, até mesmo, propedêutico.

Uma outra questão importante a ser discutida na atual conjuntura da produção é a extensão do alcance da formação oferecida pelo SENAI. Em virtude da diminuição do número de empregos formais oferecidos e da tecnologia avançada, cada vez mais presente na produção e que deve estar também nos cursos de formação, é possível indagarmos se num futuro próximo o SENAI não estará trabalhando com ilhas de excelência que correspondam a uma parcela muito pequena dos trabalhadores brasileiros. Tal questão torna-se ainda mais relevante se lembrarmos que o SENAI é financiado, sobretudo, com recursos públicos e que, conforme a pesquisa empírica reafirmou, a instituição atende, em sua maioria, aos trabalhadores já empregados, contribuindo muito pouco para 
o ingresso no sistema produtivo de indivíduos excluídos desse processo. Além disso, a opção do SENAI, de diminuir seus investimentos nos cursos de aprendizagem inicial, retrata a limitada atuação da instituição na democratização do acesso ao emprego.

A partir da pesquisa realizada, podemos afirmar que frequentar um curso técnico do Serviço Nacional de Aprendizagem Industrial, muitas vezes, não é determinante para o ingresso no mercado de trabalho. Do mesmo modo, acreditamos que apontar a falta de qualificação profissional como a principal causa do desemprego é uma análise reducionista e estratégica feita frequentemente pelo Estado e pelos representantes dos empresários.

Por fim, reafirmamos que, pela reestruturação produtiva ser um fenômeno recente, existe a necessidade de mais estudos que abordem os impactos desse fenômeno na formação profissional. Tal carência é afetada ainda pela constante dificuldade na realização de pesquisas em empresas, onde podem ser observados diretamente os efeitos da reestruturação produtiva no mundo do trabalho.

\section{Referências Bibliográficas}

ARANHA, M. L. de A. História da educação. São Paulo: Moderna, 1996.

BRASIL. Constituição. Constituição da República Federativa do Brasil. Brasília, DF: Senado, 1937.

BRASIL. Lei $\mathrm{n}^{\circ}$ 9.394, de 20 de dezembro de 1996. Estabelece as diretrizes e bases da educação nacional. Diário Oficial da União. Brasília, DF, 23 dez. 1996.

CUNHA, L. A. Ensino médio e profissional: da fusão à exclusão. 1997 (mimeo).

DELUIZ, N. O modelo das competências profissionais no mundo do trabalho e na educação: implicações para o currículo. Boletim Técnico do SENAI, Rio de Janeiro, v. 27, n. 3, Set./Dez. 2001.

DIEESE. Departamento Intersindical de Estatística e Estudos Sócio-econômicos. Boletim Pesquisa de Emprego e Desemprego, Belo Horizonte, n. 11, Nov. 2006.

EVANGELISTA, J. Sistema "S". In: FIDALGO, F., MACHADO, L. (editores). Dicionário da educação profissional. Belo Horizonte: Núcleo de Estudos sobre Trabalho e Educação, 2000, p. 309.

EVANGELISTA, J., FIDALGO, F. Fundo de Amparo ao Trabalhador - FAT. In: FIDALGO, F., MACHADO, L. (editores). Dicionário da educação profissional. Belo Horizonte: Núcleo de Estudos sobre Trabalho e Educação, 2000, p. 169.

FERREIRA, C. G. Reestruturação produtiva. In: FIDALGO, F., MACHADO, L. (editores). Dicionário da educação profissional. Belo Horizonte: Núcleo de Estudos sobre Trabalho e Educação, 2000, p. 283. 
FERRETTI, C. J. Formação profissional e reforma do ensino técnico no Brasil: anos 90. Educação e Sociedade. Campinas, n. 59, p. 225-269, 1997.

FORD, H. Minha vida e minha obra. Rio de Janeiro: Brand, s.d.

FREITAG, B. Escola, estado e sociedade. São Paulo: Moraes, 1986, 142p.

KUENZER, A. Z. Ensino Médio - construindo uma proposta para os que vivem do trabalho. São Paulo: Cortez, 2002.

LEITE, M. de P., RIZEK, C. S. Projeto: reestruturação produtiva e qualificação. Educação \& Sociedade, Campinas, v. 18, n. 58, p. 178-198, Jul. 1997.

MORAES, C. S. V. (coord.). Diagnóstico da formação profissional: o ramo metalúrgico. São Paulo: Artchip Editora, 1999.

POCHMANN, M. Mudanças na ocupação e a formação profissional. Trabalho \& Educação. Belo Horizonte, n. 6, p. 48-71, jul/dez 1999 - jan/jun 2000.

ROMANELLI, O. de O. História da educação no Brasil (1930/1973). Petrópolis: Vozes, 1982.

SEGNINI, L. R. P. Educação, trabalho e desenvolvimento: uma complexa relação. Trabalho \& Educação. Belo horizonte, n. 6, p. 14-46, jul/dez 1999 - jan/jun 2000.

SENAI. Departamento Nacional. Almanaque. 2004.

SENAI. Departamento Nacional. Relatório Anual 2005. Brasília: SENAI/DN.

TUMOLO, P. S. Reestruturação produtiva no Brasil: um balanço crítico introdutório da produção bibliográfica. Educação \& Sociedade, Campinas, n. 77, p. 71-99, dez 2001.

TAYLOR, F. Princípios da administração científica. São Paulo: Atlas, 1980.

\section{NOTAS}

\footnotetext{
${ }^{1}$ Taylor baseava seu modelo produtivo no fracionamento do trabalho (através da gerência científica da produção); assim buscava superar alguns entraves ao desenvolvimento do capitalismo americano. Entre eles, podemos destacar o fato de grande parte do processo produtivo da época ser baseado nos ofícios, em que o trabalhador possui domínio do saber produtivo. Já Ford buscava o fracionamento do produto. Dentre as idéias defendidas e implementadas por Ford, podemos destacar o minucioso planejamento da produção e a criação da esteira de produção que, segundo o próprio industrial, visava a economia dos pensamentos e dos movimentos e, conseqüentemente, a redução dos custos de produção. Além disso, Ford objetivava a criação de uma produção e de um consumo em massa, através do controle de fatores externos à fábrica relacionados ao processo produtivo capitalista. Com o objetivo de criar uma mentalidade favorável ao sistema, o interesse do capitalista volta-se também para o dia-a-dia do trabalhador, seu modo de vida, seus hábitos familiares e seus valores morais.

${ }^{2}$ Segundo Ferreira (2000, p.283), o processo de reestruturação produtiva está assentado em três eixos principais: 1) as novas tecnologias da "III Revolução Industrial" (com destaque para a automação microeletrônica, também chamada de automação flexível ou programável); 2) as mudanças organizacionais (em particular, as novas formas de organização do trabalho); 3) as inovações gerenciais e institucionais (mudanças na gestão dos recursos humanos e nas estratégias empresariais, de um modo geral).

${ }^{3}$ É um fundo público criado através da Lei n. 7.998 de janeiro de 1990. Ele é constituído com recursos provenientes das contribuições do Programa de Integração Social (PIS), do Programa de Formação do Patrimônio dos Servidores Público (PASEP) e de uma cota-parte da Contribuição Sindical. Esses recursos são utilizados para inúmeras finalidades, dentre
} 
elas para financiar ações integradas no pagamento do seguro-desemprego e do abono salarial, programas de qualificação e re-qualificação profissional (EVANGELISTA; FIDALGO, 2000, p.169).

Artigo recebido em 01/2010. Aprovado em 02/2010. 